\title{
Emerging therapies for food allergy
}

\author{
Corinne A. Keet ${ }^{1}$ and Robert A. Wood ${ }^{2}$
}

${ }^{1}$ Division of Pediatric Allergy and Immunology and ${ }^{2}$ Division of Allergy and Immunology, Department of Pediatrics, Johns Hopkins University School of Medicine, Baltimore, Maryland, USA.

\begin{abstract}
Food allergy is a common condition for which there are currently no approved treatments except avoidance of the allergenic food and treatment of accidental reactions. There are several potential treatments that are under active investigation in animal and human studies, but it is not yet clear what the best approach may be. Here, we review approaches that are currently in clinical trials, including oral, sublingual, and epicutaneous immunotherapy, immunotherapy combined with anti-IgE, and Chinese herbal medicine as well as approaches that are in preclinical or early clinical investigation, including modified protein immunotherapy, adjuvants, DNA vaccines, and helminth administration. We discuss the importance of fully exploring the risks and benefits of any treatment before it is taken to general clinical practice and the need for clarity about the goals of treatment.
\end{abstract}

\section{Introduction}

Food allergy is defined as an immunologically mediated response that occurs repeatedly on exposure to a food (1). Up to $12 \%$ of children report an allergy to one or more foods, making it one of the most common chronic diseases of childhood (1). Although food allergy encompasses both IgE-mediated disease, typically characterized by acute symptoms such as hives or respiratory distress, and non-IgE-mediated conditions, such as milk-protein proctocolitis and eosinophilic gastrointestinal diseases, this review focuses on IgE-mediated allergy.

There are currently no approved treatments for food allergy except for avoidance of the allergenic food and treatment of accidental reactions. While much childhood food allergy is outgrown, a substantial proportion of even milk and egg allergy persists into adulthood, and some food allergies, such as peanut, tree nuts, and shellfish, are usually persistent (1). Reported rates of reaction due to accidental exposure vary widely, from $5 \%$ per year to $58 \%$ per five years for peanut $(2,3)$ and up to $80 \%$ per year for milk (4). Although mortality from food-related anaphylaxis is rare, estimated to be approximately 1.8 per million person-years among foodallergic subjects (5), fear of accidental reactions and social effects of avoidance diets contribute to significantly impaired quality of life for food-allergic children and their caregivers (6). Moreover, avoidance diets can leave food-allergic children at nutritional risk (7). It is estimated that food allergy costs the US almost 25 billion dollars per year in direct and indirect expenses (8).

For all of these reasons, effective treatment for food allergy would be highly desirable. However, while potential treatments are under active investigation, it is still not at all clear what the best approach may be. Further, there is lack of consensus as to what the goals of therapy should be: while the ability to incorporate the food into the diet would be ideal, some would argue that simply minimizing the risk of reaction with accidental exposure would be of sufficient value to justify treatment. These questions are vital because we need criteria by which to evaluate novel treatments, especially if they carry risk of serious adverse reactions. In fact, whether the emerging therapies for food allergy are sufficiently beneficial to justify any significant risk remains to be determined.

Conflict of interest: Robert A. Wood receives royalties from Up-To-Date, is a consultant for the Asthma and Allergy Foundation of America, and is on the Medical Advisory Board for the Food Allergy Research and Education Foundation.

Citation for this article: J Clin Invest. 2014;124(5):1880-1886. doi:10.1172/JCI72061.

\section{Pathophysiology of food allergy}

IgE-mediated food allergy is characterized by Th2-dominant immunologic responses, with allergen-specific IgE present in circulating forms and bound to mast cells and basophils. Allergen-specific, Th2-deviated $\mathrm{CD} 4^{+} \mathrm{T}$ cells predominantly produce cytokines, such as IL-4, IL-5, IL-9, and IL-13, which promote IgE production, eosinophil proliferation, and trafficking of inflammatory cells to tissues. The predominant mechanism by which food allergy develops remains controversial, with some studies suggesting that primary sensitization through skin contact may be even more important than exposure via the gut (9). Active gastrointestinal tolerogenic mechanisms appear to be important in preventing food allergy in general, as children with genetic defects in generating regulatory $\mathrm{T}$ cells frequently have severe allergic disease (10, 11). APCs in the gut, particularly DCs, clearly direct these $\mathrm{T}$ cell responses and are themselves responsive to the context in which they receive antigen. Abnormal function of both DCs and T cells has been linked to food allergy (12-20). Contextual clues that influence DC responses include costimulatory signals through a variety of receptors, including the TLRs. These signals come from multiple sources, including those associated with tissue damage, commensal bacteria, and the allergen itself $(20,21)$. Responses to these signals may vary considerably due to genetic predisposition (22).

Although basic science has been helpful in understanding the mechanisms by which potential treatments for food allergy might work, to date, the most promising therapies have not come as a result of these discoveries but instead from clinical observation and the modification of therapies previously developed for other allergic diseases. For example, immunotherapy, discussed at length below, was first described as a treatment for IgE-mediated allergic disease in 1911 (23), more than 50 years before the discovery of IgE (24). Some therapies, such as the recombinant peanut vaccine described below, emerged from basic science and appeared effective in animal models, but failed when tested in humans. Still other approaches, such as DNA vaccines, which appear promising in animal models, may be difficult or impossible to safely translate to humans. In the following sections, we will first review approaches that are under active clinical investigation, after which we will review potential approaches that are in preclinical or early clinical investigation.

\section{Current clinical investigations}

Current clinical investigations are summarized in Table 1. For venom and aero allergies, immunotherapy using intact, and often 
Table 1

Selected recent clinical studies

\begin{tabular}{|c|c|c|c|c|c|c|}
\hline $\begin{array}{l}\text { Selected recent } \\
\text { clinical studies }\end{array}$ & $\begin{array}{l}\text { Drug name } \\
\text { (if any) }\end{array}$ & $\begin{array}{l}\text { Foods studied/ } \\
\text { description }\end{array}$ & $\begin{array}{l}\text { Types of studies } \\
\text { done }\end{array}$ & Efficacy & Safety & $\begin{array}{c}\text { Selected } \\
\text { references }\end{array}$ \\
\hline \multicolumn{7}{|c|}{ Allergen-specific immunotherapies } \\
\hline Oral immunotherapy & N/A & $\begin{array}{l}\text { Milk, egg, peanut, } \\
\text { others }\end{array}$ & $\begin{array}{l}\text { Small to medium } \\
\text { phase } 1 / I I\end{array}$ & $\begin{array}{l}>60 \% \text { desensitized } \\
\text { in most studies }\end{array}$ & $\begin{array}{c}10 \%-20 \% \text { rate } \\
\text { of withdrawal for AEs }\end{array}$ & $28,30-74$ \\
\hline Sublingual immunotherap & NA & $\begin{array}{c}\text { Milk, peanut, } \\
\text { hazelnut, others }\end{array}$ & Small phase I/II & $\begin{array}{l}\text { High rate of partial } \\
\text { desensitization, full } \\
\text { desensitization rare }\end{array}$ & $\begin{array}{l}\text { Appears safer than } \\
\text { oral immunotherapy }\end{array}$ & 47,76 \\
\hline $\begin{array}{l}\text { Oral immunotherapy } \\
\text { plus omalizumab } \\
\text { (anti-lgE) }\end{array}$ & Omalizumab & Milk, peanut & Small phase I & $\begin{array}{l}\text { Desensitization } \\
\text { in } 80 \%-90 \%\end{array}$ & $\begin{array}{l}\text { Up to } 10 \% \text { rate of } \\
\text { withdrawal for AEs } \\
\text { in rush protocols }\end{array}$ & 88,89 \\
\hline Recombinant protein & EMP-123 & $\begin{array}{l}\text { Rectally administered, } \\
\text { recombinant peanut } \\
\text { within E. coli }\end{array}$ & Small phase I & NA & $\begin{array}{l}50 \% \text { withdrawal for } \\
\text { AEs, } 20 \% \text { anaphylaxis }\end{array}$ & 113 \\
\hline Epicutaneous patch & ViaSkin, others & $\begin{array}{l}\text { Epicutaneous } \\
\text { patch for milk }\end{array}$ & Phase I/II & Unknown & Well tolerated & 96 \\
\hline \multicolumn{7}{|l|}{ Nonspecific } \\
\hline Chinese herbal medicine & FAHF-2 & $\begin{array}{l}\text { Mixture of traditional } \\
\text { Chinese medicine herbs }\end{array}$ & Phase I trials & Unknown & Well tolerated & 104,106 \\
\hline Anti-lgE & $\begin{array}{l}\text { Omalizumab, } \\
\text { TNX-901 }\end{array}$ & Peanut & Phase I trials & $\begin{array}{l}\text { At least partial } \\
\text { desensitization in } \\
\text { most subjects }\end{array}$ & Well tolerated & 81,82 \\
\hline
\end{tabular}

$A E$, adverse event.

rather crude, allergens remains the only disease-modifying therapy available. Although sublingual delivery is emerging as a treatment option for inhalant allergens, especially in Europe, most immunotherapy has traditionally been provided by s.c. injection of gradually increasing allergen doses over months, followed by several years of maintenance dosing. Limited study of s.c. injection for food allergy, however, resulted in unacceptably high rates of systemic side effects (25) such that subsequent approaches under investigation have attempted to improve this risk/benefit ratio through a variety of methods, including different routes of delivery, modification of the allergens, cotreatment with medications to reduce adverse reactions, and the use of adjuvants to achieve maximum benefit at the lowest possible allergen dose.

Oral and sublingual immunotherapy. Published case reports of sublingual immunotherapy or oral immunotherapy for the treatment of food allergy date back to at least 1908 through the 1940s (26-29), but the first randomized, placebo-controlled study of either method was not published until 2005 (30). In recent years, there has been a proliferation of small and medium-sized studies of these methods $(28,30-74)$, but small sample sizes and variable study designs have made interpretation of the evidence difficult. A Cochrane review of milk oral immunotherapy (75) up to October 2012 found five trials that met their quality criteria, with a total of 196 patients. Of these trials, only three were blinded with a placebo arm, and each study used a different protocol. In total, $62 \%$ of the treated group was able to consume a full serving of milk at the end of the treatment, compared with $8 \%$ of the control subjects. An additional $25 \%$ of treated subjects could consume a partial serving of milk. The rate of adverse events was difficult to summarize because of the variability between studies, but overall, $9 \%$ of treated subjects required epinephrine.
These findings are similar to other controlled studies of oral immunotherapy. A multi-center, randomized, placebo-controlled trial of egg oral immunotherapy conducted by the Consortium for Food Allergy Research (CoFAR) in 55 children found that $55 \%$ were able to consume a 5 -gram serving of egg after 10 months of therapy compared with $0 \%$ of placebo-treated patients. After an additional 12 months of therapy, $75 \%$ of those on active treatment were able to consume a full 10-gram serving (53). For peanut, a randomized, placebo-controlled trial of oral immunotherapy in 28 children found that $84 \%$ were able to tolerate a 5 -gram challenge at one year compared with none of the placebo subjects (44). Most of the studies have been done in school-aged children, but a randomized trial of 60 toddlers found that milk oral immunotherapy was also effective in young children, with $90 \%$ of treated subjects tolerating the full challenge compared with $23 \%$ of control subjects (72). Generally, these early studies with motivated volunteers have had a $10 \%-20 \%$ dropout rate for adverse events, typically gastrointestinal side effects or acute reactions. Eosinophilic esophagitis has been reported in some studies, and it is not clear how frequently undiagnosed disease may complicate immunotherapy. Oral symptoms are very common with dosing, and moderate side effects, while generally occurring with less than $2 \%$ of doses $(53,76)$, affect a high percentage of participants because doses are administered daily. For example, in the study of young children, $47 \%$ of subjects developed moderate reactions during treatment (72).

Fewer studies have been done with sublingual immunotherapy, but thus far it appears that efficacy is much less than with oral immunotherapy. A CoFAR placebo-controlled study of peanut sublingual immunotherapy in 40 adolescents and adults found that $70 \%$ of treated subjects increased their food challenge thresh- 


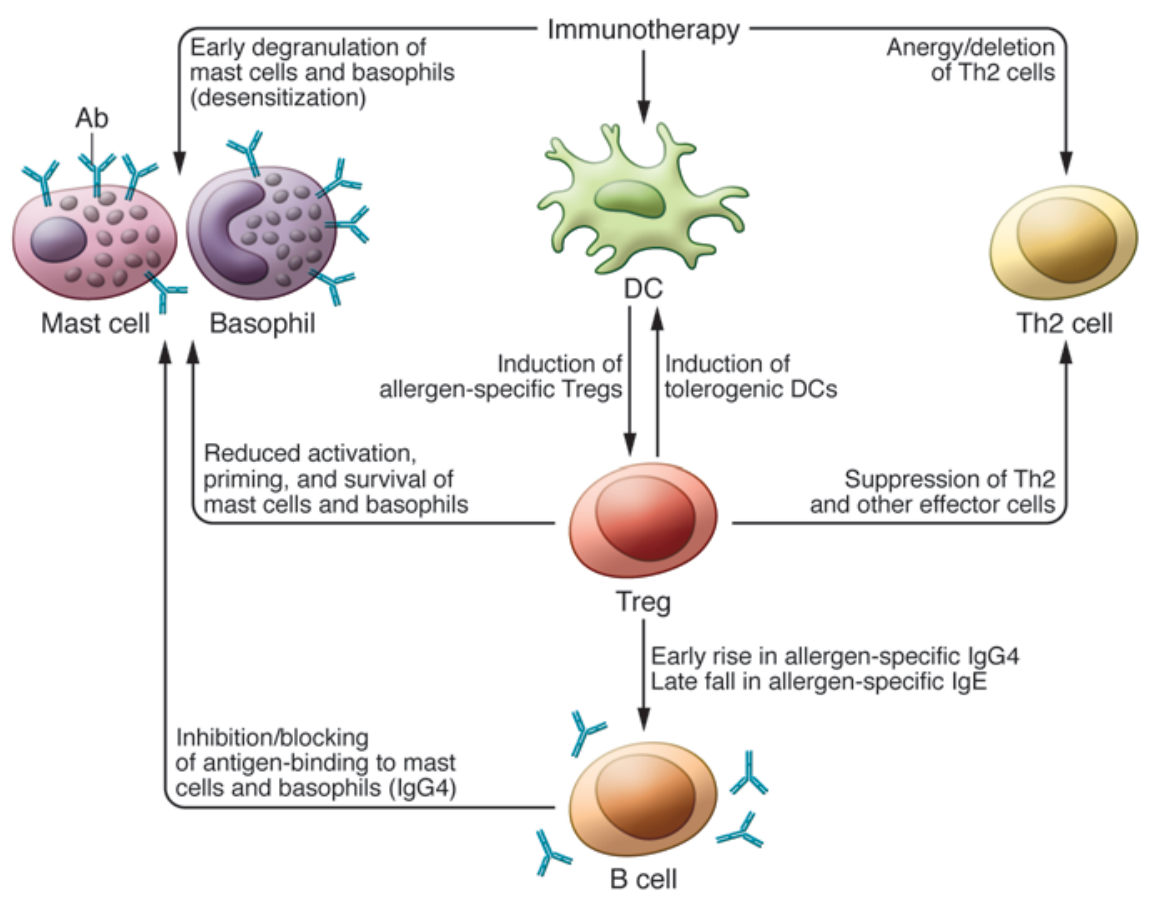

\section{Figure 1}

Potential mechanisms by which specific immunotherapy to food may act. Multiple cellular responses to immunotherapy may contribute to reduced immune activation, including deletion of effector Th2 cells, desensitization of mast cells and basophils, and induction of tolerogenic DCs. In addition, immunotherapy may promote allergen-specific Tregs, which in turn suppress effector T cells, reduce activation of mast cells and basophils, and trigger B cells to first increase IgG4 production and then decrease IgE production, leading to decreased activation of mast cells and basophils. Mechanisms of other therapeutic approaches (not shown) may include (a) inhibition of IgE binding (anti-lgE), (b) reduced basophil activation (FAHF-2), (c) reduced Th2 responses (FAHF-2, helminths), and (d) induction of tolerogenic DCs (DNA vaccines). old by at least 10 -fold at 44 weeks, compared with $15 \%$ of placebotreated subjects, but none of the treated subjects were able to pass a full food challenge at that time (47). Our group compared milk oral immunotherapy to sublingual immunotherapy in 30 children and found that after approximately 18 months, $70 \%$ of oral immunotherapy subjects could tolerate a full serving of milk compared with $10 \%$ of sublingual immunotherapy subjects (76). However, sublingual immunotherapy appears to be safer than oral immunotherapy, with significantly fewer multi-system, gastrointestinal, and lower respiratory reactions (76).

It is likely that the differences between oral immunotherapy and sublingual immunotherapy, with regard to both efficacy and safety, primarily represent differences in the antigen doses that are used, given that typical sublingual immunotherapy maintenance doses are under $10 \mathrm{mg}$ compared with 1 to 4 grams for oral immunotherapy. Improved sublingual immunotherapy efficacy might therefore be possible if higher doses were used, and in theory, an ideal sublingual immunotherapy dose might achieve efficacy similar to oral immunotherapy at far lower - and therefore safer - doses, given the high density of tolerogenic APCs in the sublingual space (77). However, significantly higher sublingual immunotherapy doses will not be possible unless more concentrated extracts or alternative delivery systems, such as the tablets that have been formulated for grass pollen sublingual immunotherapy (78), are developed. Until then, maximum sublingual immunotherapy dosing will remain limited by the concentration of the available aqueous extracts and the volume of liquid that can be safely administered sublingually.

The mechanisms of action underlying oral immunotherapy and sublingual immunotherapy are not entirely clear, although it is likely that a combination of suppressive mechanisms, anergy, and deletion of reactive T cells is important (refs. 21, 35, and Figure 1). With treatment, allergen-specific IgE tends to rise initially and then fall marginally by the completion of treatment. Specific IgG4 levels increase, and markers of basophil activation and mast cell reactivity (as evidenced by skin test responses) typically decrease
$(47,53,76)$. Although these changes occur in most subjects, especially with oral immunotherapy, and may be associated with more positive outcomes, the data thus far do not allow for any of these measures to be used as reliable biomarkers of clinical response.

Although short-term desensitization appears to be common with oral immunotherapy, the prospect for complete resolution of allergy - or even a sustained period of unresponsiveness (also sometimes called "clinical tolerance") - appears to be limited with current methods. Although the persistence of desensitization after avoidance of the allergen has only been assessed in a few studies, the results are sobering overall. In our study of milk allergy, $40 \%$ of subjects desensitized with oral immunotherapy remained unresponsive at six weeks, and some regained reactivity within a week (76). Similarly, in the egg oral immunotherapy study, only $36 \%$ of desensitized subjects had sustained unresponsiveness four to six weeks after the discontinuation of therapy (39). This concept is very important because if sustained protection is not the norm, the long-term safety of food immunotherapy after treatment may be far more problematic than the known short-term risks during treatment. Although data on long term outcomes are limited, we recently reported in a follow-up of two milk oral immunotherapy studies three to five years after study completion that only $25 \%$ of subjects were consuming normal servings of milk without any symptoms, that almost $30 \%$ were having regular or predictable symptoms, and that, most concerning, almost $20 \%$ had anaphylaxis during the follow-up period, including some who appeared to have had an excellent response to treatment (79). While ongoing consumption of the problem food may afford protection for most, this does not appear to always be the case and, even if it were, this is something that can be difficult to achieve, even in the research setting (80).

Anti-IgE therapy. Anti-IgE agents such as TNX-901 and omalizum$\mathrm{ab}$, which is licensed for the treatment of asthma, have been shown to increase the food challenge threshold to peanut. These treatments have the advantage over immunotherapy that they are non-allergen 
specific and thus may be effective for those who are allergic to multiple foods. However, their effects are dependent on continued injections of the antibody $(81,82)$, and this treatment is very expensive.

Theoretically, addition of an anti-IgE antibody alongside oral immunotherapy might reduce the rate of adverse events and/or improve long-term outcomes. In conjunction with s.c. injection using aeroallergens, omalizumab improved the tolerability of dose escalation while retaining and perhaps improving the long-lasting benefits of immunotherapy (83-87). Two small, uncontrolled studies of omalizumab combined with rush food oral immunotherapy, where dose escalation was performed at a more rapid pace than usual using either peanut or milk, have recently been published. In the first, nearly all subjects were able to complete dose escalation, but $40 \%$ of subjects experienced a grade 2 or 3 adverse event, defined as the presence of moderate to severe symptoms (88). In the second, $30 \%$ of subjects still had reactions requiring epinephrine (89). Thus, although omalizumab may improve the tolerability of oral immunotherapy, it may only benefit a subset of patients, and determination of its specific role awaits the results of controlled studies that are currently underway (ClinicalTrials.gov identifier: NCT01157117).

Epicutaneous immunotherapy and other routes of immunotherapy. Recently, there has been increasing interest in the potential to deliver immunotherapy via the skin and other routes. It has now been shown that with epicutaneous (e.c.) immunotherapy, antigen presented to intact skin is captured by DCs and brought to regional lymph nodes (90) and that, in the mouse, allergen administered through intact skin reduced Th2 responses to subsequent oral allergen challenge (91-94). The largest e.c. immunotherapy study to date was of grass pollen allergy, where e.c. immunotherapy reduced pollen-related symptoms during the posttreatment pollen season. Although the overall e.c. immunotherapy safety profile appears reassuring, approximately $10 \%$ of subjects had reactions during dosing requiring antihistamines, and mild local reactions were common (95). A pilot study of e.c. immunotherapy in 19 cow's milk-allergic children showed good tolerability but no change in food challenge threshold after three months of treatment (96). Currently, a phase 2 trial of peanut e.c. immunotherapy is being conducted within the CoFAR network with the long-term hope being that e.c. immunotherapy can induce changes similar to oral immunotherapy with fewer systemic side effects (ClinicalTrials.gov identifier: NCT01904604). Other routes of therapy, including intradermal and intralymphatic immunotherapy, are also showing promising results in preclinical and clinical trials of other allergens (97-101).

Chinese herbal medicine. A product with the proprietary name Food Allergy Herbal Formula-2 (FAHF-2) is a novel formulation of nine herbs that are commonly used in Chinese traditional medicine for the treatment of gastroenteritis, asthma, and allergic rhinitis (102). In a murine model and in human B cell lines, one component, Rubia cordifolia, inhibited peanut-triggered $\operatorname{IgE}$ production, while another, Dianthus superbus, inhibited peanutinduced anaphylactic reactions. The mechanism appears to be partially related to suppression of Th2 responses and enhancement of Th1 responses, as production of IL-4, IL-5, and IL-13 was significantly reduced with treatment, while IFN- $\gamma$ production increased (103). In the murine model, suppression of anaphylactic reactions lasted at least six months after treatment $(104,105)$.

Preliminary data from human pilot studies suggest that FAHF-2 is safe and well tolerated and showed immunologic effects, including decreased IL-5 levels and basophil activation, as measured by
CD63 expression $(104,106)$. A controlled efficacy study is currently being conducted in adolescents and adults (ClinicalTrials. gov identifier: NCT00602160), and studies using FAHF-2 along with oral immunotherapy will hopefully begin in the near future.

\section{Novel therapeutic strategies in preclinical or early clinical investigation}

Modified protein immunotherapy. Immunotherapy with proteins that are modified so that IgE-binding epitopes are removed or significantly altered, while maintaining relevant $\mathrm{T}$ cell binding, could provide efficacy similar to that of the unmodified protein, with an improved safety profile. This approach could theoretically make it possible to induce tolerance with far shorter courses of therapy by safely providing higher doses of the tolerogenic epitopes with little or no need for gradual dose escalation. Two general approaches are under investigation, one relying on the modification of the IgEbinding sites to reduce reactivity and the second based upon the identification of specific tolerogenic epitopes that are spliced from the larger molecule and provided as "peptide immunotherapy." The latter approach is now in phase 3 trials for cat allergen (107, $108)$ and is being actively pursued in preclinical trials for other allergens, including egg and fish $(109,110)$.

The former approach has been applied to peanut allergy by developing a recombinant vaccine in which the IgE-binding epitopes on the three major peanut allergens, Ara h1, h2, and h3, were modified by single amino acid substitutions, then encapsulated in inactivated E. coli (EMP-123). In mouse models, the modified allergens did not bind IgE or induce basophil reactivity (111); however, they reduced anaphylactic symptoms on rechallenge with allergen in sensitized animals (112). In spite of the encouraging results in the animal model, a recent phase I trial of EMP-123 administered per rectum was disappointing (113). In fact, acute allergic reactions were so common that five of ten peanut-allergic subjects were unable to complete dosing, indicating that $\operatorname{IgE}$ binding was not adequately reduced by this modification.

Adjuvants. Another promising approach is to combine the immunotherapeutic protein - either intact or modified - with other components to enhance tolerogenic responses. For example, the TLR9 agonist CpG oligodeoxynucleotide leads to a Th1-skewed DC response. Further, linking $\mathrm{CpG}$ with allergen has reduced anaphylactic reactions to allergen when used either as a preventative therapy or as treatment in the form of s.c. injection or e.c. immunotherapy (114-118) in murine models. In humans, a similar TLR9 agonist, phosphorothioate oligodeoxyribonucleotide DNA, was coupled to ragweed antigen and showed some efficacy in a pilot s.c. injection study (119). Another potential adjuvant is chitosan, a polymer commonly found in the cell walls of fungi and many invertebrates, which activates macrophages and modulates Th2 inflammation (119-121). Mice fed chitosan did not exhibit orally induced peanut sensitization and had reduced IL-4, IL-5, and IL-10 production and increased IFN- $\gamma(119-121)$. A more direct approach is to fuse inhibitory human molecules, in this case the human IgG Fc $\gamma$ I, to allergen. Linking Fc $\gamma \mathrm{I}$ directly to Ara h2 causes aggregation of the inhibitory receptor FcyRIIb and the high-affinity IgE receptor FceRI and thus inhibits degranulation of mast cells and basophils. In a murine model, s.c. treatment with FcyI-Ara h2 inhibited anaphylaxis to peanut (122). However, the likelihood of efficacy in humans and the long-term disease-modifying potential of these therapies are unclear. Although we are not aware of any current human trials using these or other adjuvant strategies for the treatment of food allergy, it is critical that 
these be pursued in future trials, as they may be the best means of optimizing outcome with therapies that might permit the use of lower allergen doses over shorter treatment periods.

DNA vaccines. A distinct immunotherapeutic approach is to eschew protein administration altogether and instead provide exposure to allergen in the form of DNA. Using a variety of vectors, DNAencoding allergen is administered and then incorporated into APCs, where it is ultimately translated into protein, potentially leading to Th1-biased responses (123). In a mouse model, oral gene delivery with chitosan-DNA nanoparticles protected against the development of peanut allergy (123). In humans, DNA vaccines for infectious diseases exhibit only modest immunological effects and have not yet shown efficacy when used alone (124). For allergy, a DNAplasmid vaccine for treatment of Japanese red cedar allergy is currently in phase I trials (ClinicalTrials.gov identifiers: NCT01707069 and NCT01966224). Although the limited human trials conducted thus far have shown good tolerability, the possibility that DNA may be integrated into the host genome remains a concern and may limit application to food allergy. Further, this approach shows more promise for prevention than it does for treatment, and while preventative strategies are certainly desirable, more general approaches would be preferable to food-specific approaches such as these.

Helminth administration. In an extension of the hygiene hypothesis, which states that the relative lack of infectious exposures of modern life has contributed to the epidemic of allergic diseases, some researchers have tried administration of helminths for control of allergic diseases, including allergic rhinitis and pecan allergy. Helminths secrete a variety of factors known to inhibit B cell and mast cell activity (125). In small studies of allergic and autoimmune diseases done thus far, administration of Trichuris suis (pig whipworm) was relatively well tolerated, with some gastrointestinal side effects and eosinophilia, but efficacy for allergic diseases has not yet been shown (125).

\section{Effects on clinical practice}

Although the FDA has not licensed any of these treatments for food allergy and most experts strongly oppose their use in current clinical practice, both oral immunotherapy and sublingual immunotherapy are being used increasingly in practice settings (126). Is this a justifiable practice? On the one hand, there is accumulating evidence that desensitization can be widely achieved with current protocols. On the other, the safety data we do have indicate that oral immunotherapy is a more risky treatment than we normally tolerate for diseases of this severity, with a relatively high per-patient rate of systemic reactions. Reactions can be unpredictable, with factors such as illness and menses that can lead to reactions with previously tolerated doses (34). Unlike s.c. injection, oral immunotherapy and sublingual immunotherapy are administered at home, without medical supervision. Most concerning, however, is our lack of understanding of the long-term trajectory of patients treated with oral immunotherapy or sublingual immunotherapy and whether they are durably protected from serious reactions. Patients and their families who choose these therapies may not fully understand the risk/ benefit ratio, especially if they are being treated in clinical settings without informed consent. Although some patients and providers may believe that these therapies, especially oral immunotherapy, will limit the risk of serious or fatal reactions from food, there are currently no data that show a decreased rate of serious life-threatening reactions with oral immunotherapy, much less cost-effectiveness. In fact, all placebo-controlled trials show a higher rate of serious reactions overall in treated subjects, and it is our clear impression that the risk of significant adverse reactions is far higher in those being treated than in those practicing strict avoidance $(47,53)$. These risks may be justified depending on the long-term treatment outcome, but long-term results are currently unavailable, and studies to date are certainly not reassuring. More research is clearly needed to understand both sides of the risk/benefit equation and to optimize therapy to reduce risks. In addition, research should address patient preferences and quality of life with these therapies.

\section{Future directions}

Future research will likely maintain some form of immunotherapy at its core and focus on increasing efficacy and/or safety. It is possible that some therapies may provide a level of desensitization that protects from accidental reactions but does not eliminate all reactivity. It may also be possible that long-term, even lifetime, treatment with all of these therapies may be needed to sustain protection. Adjuvants, recombinant or pepsinized proteins, DNA vaccines, and/or cotreatment with anti-IgE or Chinese herbs could all allow for safer and more effective therapy, but additional research is clearly needed. In the next decade, despite concerns about safety and efficacy, we do anticipate the wide use of food immunotherapy in general practice, but our hope for the next two to three decades is that therapies can be developed that are both safer and more effective and include the induction of sustained protection, or even true immunologic tolerance, for the vast majority of patients with persistent, severe food allergy.

\section{Acknowledgments}

Corinne A. Keet receives research support from the National Institute of Allergy and Infectious Diseases (NIAID), the National Institute of Child Health and Human Development (NICHD), and the Gerber Family Foundation. Robert A. Wood receives research support from the NIAID, the Initial Training Network (ITN), and the Food Allergy Research and Education Foundation. This work was funded in part by grant 1K23AI103187-01 (NIAID).

Address correspondence to: Corinne A. Keet, Johns Hopkins Hospital, CMSC 1102, 600 N. Wolfe St., Baltimore, Maryland 21202, USA. Phone: 410.955.5883; Fax: 410.955.0229; E-mail: ckeet1@ jhmi.edu.
1. Boyce JA, et al. Guidelines for the diagnosis and
management of food allergy in the United States:
report of the NIAID-sponsored expert panel.
J Allergy Clin Immunol. 2010;126(6 suppl):S1-S58.
2. Neuman-Sunshine DL, et al. The natural history of
persistent peanut allergy. Ann Allergy Asthma Immu-
nol. 2012;108(5):326-331.
3. Vander Leek TK, Liu AH, Stefanski K, Blacker B,
Bock SA. The natural history of peanut allergy
in young children and its association with serum
peanut-specific IgE. JPediatr. 2000;137(6):749-755.
4. Fleischer DM, et al. Allergic reactions to foods in preschool-aged children in a prospective observational food allergy study. Pediatrics. 2012; 130(1):e25-e32.

5. Umasunthar $T$, et al. Incidence of fatal food anaphylaxis in people with food allergy: a systematic review and meta-analysis. Clin Exp Allergy. 2013;43(12):1333-1341

6. Flokstra-de Blok BM, Dubois AE. Quality of life measures for food allergy. Clin Exp Allergy. 2012;42(7):1014-1020.

7. Sova C, et al. Systematic review of nutrient intake and growth in children with multiple IgE-mediated food allergies. Nutr Clin Pract. 2013;28(6):669-675.

8. Gupta R, Holdford D, Bilaver L, Dyer A, Holl JL, Meltzer D. The economic impact of childhood food allergy in the United States. JAMA Pediatr. 2013;167(11):1026-1031.

9. Dunkin D, Berin MC, Mayer L. Allergic sensitization can be induced via multiple physiologic routes in an adjuvant-dependent manner. J Allergy Clin Immunol. 2011;128(6):1251-1258.

10. Frischmeyer-Guerrerio PA, et al. TGF $\beta$ receptor mutations impose a strong predisposition for human allergic disease. Sci Transl Med. 2013; 
5(195):195ra194.

11. Zennaro D, et al. Proteomics plus genomics approaches in primary immunodeficiency: the case of immune dysregulation, polyendocrinopathy, enteropathy, X-linked (IPEX) syndrome. Clin Exp Immunol. 2012;167(1):120-128.

12. Man AL, Bertelli E, Regoli M, Chambers SJ, Nicoletti C. Antigen-specific T cell-mediated apoptosis of dendritic cells is impaired in a mouse model of food allergy. J Allergy Clin Immunol. 2004;113(5):965-972.

13. Blazquez AB, Berin MC. Gastrointestinal dendritic cells promote Th2 skewing via OX40L.J Immunol. 2008;180(7):4441-4450.

14. Ganeshan K, Neilsen CV, Hadsaitong A, Schleimer $\mathrm{RP}$, Luo X, Bryce PJ. Impairing oral tolerance promotes allergy and anaphylaxis: a new murine food allergy model. J Allergy Clin Immunol. 2009;123(1):231-238

15. Yang PC, et al. TIM-4 expressed by mucosal dendritic cells plays a critical role in food antigenspecific Th2 differentiation and intestinal allergy. Gastroenterology. 2007;133(5):1522-1533.

16. Frischmeyer-Guerrerio PA, et al. Dendritic cell and $\mathrm{T}$ cell responses in children with food allergy. Clin Exp Allergy. 2011;41(1):61-71.

17. Beyer K, Castro R, Feidel C, Sampson HA. Milkinduced urticaria is associated with the expansion of $\mathrm{T}$ cells expressing cutaneous lymphocyte antigen. J Allergy Clin Immunol. 2002;109(4):688-693.

18. Karlsson MR, Rugtveit J, Brandtzaeg P. Allergenresponsive $\mathrm{CD} 4+\mathrm{CD} 25+$ regulatory $\mathrm{T}$ cells in children who have outgrown cow's milk allergy. J Exp Med. 2004;199(12):1679-1688.

19. Shreffler WG, Wanich N, Moloney M, NowakWegrzyn A, Sampson HA. Association of allergenspecific regulatory $T$ cells with the onset of clinical tolerance to milk protein. J Allergy Clin Immunol. 2009;123(1):43-52.

20. Ruiter B, Shreffler WG. The role of dendritic cells in food allergy. J Allergy Clin Immunol. 2012;129(4):921-928.

21. Berin MC, Mayer L. Can we produce true tolerance in patients with food allergy? J Allergy Clin Immunol. 2013;131(1):14-22.

22. Kauffmann F, Demenais F. Gene-environment interactions in asthma and allergic diseases: challenges and perspectives. J Allergy Clin Immunol. 2012;130(6):1229-1240.

23. Ring J, Gutermuth J. 100 years of hyposensitization: history of allergen-specific immunotherapy (ASIT). Allergy. 2011;66(6):713-724.

24. Ishizaka K, Ishizaka T. Physico-chemical properties of human reaginic antibody. IV. Presence of a unique immunoglobulin as a carrier of reaginic activity. J Immunol. 1966;97(1):75-85.

25. Oppenheimer JJ, Nelson HS, Bock SA, Christensen F, Leung DY. Treatment of peanut allergy with rush immunotherapy. J Allergy Clin Immunol. 1992;90(2):256-262.

26. Schofield AT. A case of egg poisoning. Lancet. 1908;171(4410):716.

27. Edwards HE. Oral desensitization in food allergy. Can Med Assoc J. 1940;43(3):234-236.

28. Patriarca C, et al. Oral specific hyposensitization in the management of patients allergic to food. Allergol Immunopathol (Madr). 1984;12(4):275-281.

29. Potemkina AM, Timerbaeva GM. [Specific desensitization treatment of children with food hypersensitivity by the sublingual method]. Pediatriia. 1982; (2):38-40.

30. Enrique E, et al. Sublingual immunotherapy for hazelnut food allergy: a randomized, doubleblind, placebo-controlled study with a standardized hazelnut extract. J Allergy Clin Immunol. 2005;116(5):1073-1079.

31. Yu GP, Weldon B, Neale-May S, Nadeau KC. The safety of peanut oral immunotherapy in peanut- allergic subjects in a single-center trial. Int Arch Allergy Immunol. 2012;159(2):179-182.

32. Meglio P, Giampietro PG, Gabriele I, Carello R, Avitabile S, Galli E. Oral desensitisation with food is food-specific and protein-specific. Int J Immunopathol Pharmacol. 2011;24(3):803-811.

33. Anagnostou K, Clark A, King Y, Islam S, Deighton J, Ewan P. Efficacy and safety of high-dose peanut oral immunotherapy with factors predicting outcome. Clin Exp Allergy. 2011;41(9):1273-1281.

34. Varshney $\mathrm{P}$, et al. Adverse reactions during peanut oral immunotherapy home dosing. J Allergy Clin Immunol. 2009;124(6):1351-1352.

35. Jones SM, et al. Clinical efficacy and immune regulation with peanut oral immunotherapy. J Allergy Clin Immunol. 2009;124(2):292-300.

36. Hofmann AM, et al. Safety of a peanut oral immunotherapy protocol in children with peanut allergy. J Allergy Clin Immunol. 2009;124(2):286-291.

37. Clark AT, Islam S, King Y, Deighton J, Anagnostou $\mathrm{K}$, Ewan PW. Successful oral tolerance induction in severe peanut allergy. Allergy. 2009;64(8):1218-1220.

38. Vickery BP, Pons L, Kulis M, Steele P, Jones SM, Burks AW. Individualized IgE-based dosing of egg oral immunotherapy and the development of tolerance. Ann Allergy Asthma Immunol. 2010;105(6):444-450.

39. Burks AW, Jones SM. Egg oral immunotherapy in non-anaphylactic children with egg allergy: followup. J Allergy Clin Immunol. 2008;121(1):270-271.

40. Staden U, Rolinck-Werninghaus C, Brewe F, Wahn U, Niggemann B, Beyer K. Specific oral tolerance induction in food allergy in children: efficacy and clinical patterns of reaction. Allergy. 2007;62(11):1261-1269.

41. Patriarca $G$, et al. Oral specific desensitization in foodallergic children. Dig Dis Sci. 2007;52(7):1662-1672.

42. Buchanan AD, et al. Egg oral immunotherapy in nonanaphylactic children with egg allergy. J Allergy Clin Immunol. 2007;119(1):199-205.

43. Patriarca G, Schiavino D, Nucera E, Schinco G, Milani A, Gasbarrini GB. Food allergy in children: results of a standardized protocol for oral desensitization. Hepatogastroenterology. 1998;45(19):52-58.

44. Varshney $P$, et al. A randomized controlled study of peanut oral immunotherapy: clinical desensitization and modulation of the allergic response. J Allergy Clin Immunol. 2011;127(3):654-660.

45. Blumchen $\mathrm{K}$, et al. Oral peanut immunotherapy in children with peanut anaphylaxis. J Allergy Clin Immunol. 2010;126(1):83-91.

46. Itoh N, Itagaki Y, Kurihara K. Rush specific oral tolerance induction in school-age children with severe egg allergy: one year follow up. Allergol Int. 2010;59(1):43-51

47. Fleischer DM, et al. Sublingual immunotherapy for peanut allergy: a randomized, double-blind, placebo-controlled multicenter trial. J Allergy Clin Immunol. 2013;131(1):119-117.

48. Chin SJ, et al. Sublingual versus oral immunotherapy for peanut-allergic children: a retrospective comparison. J Allergy Clin Immunol. 2013;132(2):476-478.

49. Kim EH, et al. Sublingual immunotherapy for peanut allergy: clinical and immunologic evidence of desensitization. J Allergy Clin Immunol. 2011;127(3):640-646.

50. Ojeda P, Ojeda I, Rubio G, Pineda F. Home-based oral immunotherapy protocol with pasteurized egg for children allergic to hen's egg. Isr Med Assoc J. 2012;14(1):34-39.

51. Ruiz Garcia M, Haroun E, Landivar ME, Torres Hernandez JA, Sastre J. Commercial dehydrated egg white for specific oral tolerance induction (SOTI): an easier treatment for egg allergy. J Investig Allergol Clin Immunol. 2012;22(7):529-531.

52. Fuentes-Aparicio V, et al. Oral immunotherapy in hen's egg-allergic children increases a hypo-proliferative subset of CD4+ T cells that could constitute a marker of tolerance achievement. Pediatr Allergy
Immunol. 2012;23(7):648-653.

53. Burks AW, et al. Oral immunotherapy for treatment of egg allergy in children. $N$ Engl J Med. 2012;367(3):233-243

54. Garcia Rodriguez R, et al. Oral rush desensitization to egg: efficacy and safety. Clin Exp Allergy. 2011;41(9):1289-1296.

55. Vazquez-Ortiz M, et al. Safety and predictors of adverse events during oral immunotherapy for milk allergy: severity of reaction at oral challenge, specific IgE and prick test. Clin Exp Allergy. 2013;43(1):92-102.

56. Pajno GB, et al. Oral immunotherapy for cow's milk allergy with a weekly up-dosing regimen: a randomized single-blind controlled study. Ann Allergy Asthma Immunol. 2010;105(5):376-381.

57. Staden U, et al. Rush oral immunotherapy in children with persistent cow's milk allergy. J Allergy Clin Immunol. 2008;122(2):418-419.

58. Skripak JM, et al. A randomized, double-blind, placebo-controlled study of milk oral immunotherapy for cow's milk allergy. J Allergy Clin Immunol. 2008;122(6):1154-1160.

59. Garcia-Ara C, Pedrosa M, Belver MT, MartinMunoz MF, Quirce S, Boyano-Martinez T. Efficacy and safety of oral desensitization in children with cow's milk allergy according to their serum specific IgE level. Ann Allergy Asthma Immunol. 2013;110(4):290-294.

60. Alvaro M, et al. Specific oral desensitization in children with IgE-mediated cow's milk allergy. Evolution in one year. Eur J Pediatr. 2012;171(9):1389-1395.

61. Mori F, Pucci N, Rossi ME, de Martino M, Azzari C, Novembre E. Oral desensitization to milk: how to choose the starting dose! Pediatr Allergy Immunol. 2010;21(2 pt 2):e450-e453.

62. Kaneko H, et al. Efficacy of the slow dose-up method for specific oral tolerance induction in children with cow's milk allergy: comparison with reported protocols. J Investig Allergol Clin Immunol. 2010;20(6):538-539.

63. Narisety SD, et al. Open-label maintenance after milk oral immunotherapy for IgE-mediated cow's milk allergy. J Allergy Clin Immunol. 2009;124(3):610-612.

64. Caminiti L, et al. A new protocol for specific oral tolerance induction in children with IgEmediated cow's milk allergy. Allergy Asthma Proc. 2009;30(4):443-448

65. Zapatero L, Alonso E, Fuentes V, Martinez MI. Oral desensitization in children with cow's milk allergy. J Investig Allergol Clin Immunol. 2008;18(5):389-396.

66. Meglio P, Giampietro PG, Gianni S, Galli E. Oral desensitization in children with immunoglobulin E-mediated cow's milk allergy - follow-up at $4 \mathrm{yr}$ and 8 months. Pediatr Allergy Immunol. 2008;19(5):412-419.

67. Longo G, et al. Specific oral tolerance induction in children with very severe cow's milk-induced reactions. J Allergy Clin Immunol. 2008;121(2):343-347.

68. Martorell Aragones A, Felix Toledo R, Cerda Mir JC, Martorell Calatayud A. Oral rush desensitization to cow milk. Following of desensitized patients during three years. Allergol Immunopathol (Madr). 2007;35(5):174-176.

69. Morisset M, et al. Oral desensitization in children with milk and egg allergies obtains recovery in a significant proportion of cases. A randomized study in 60 children with cow's milk allergy and 90 children with egg allergy. Eur Ann Allergy Clin Immunol. 2007;39(1):12-19.

70. Meglio P, Bartone E, Plantamura M, Arabito E, Giampietro PG. A protocol for oral desensitization in children with IgE-mediated cow's milk allergy. Allergy. 2004;59(9):980-987.

71. Barbi E, et al. Adverse effects during specific oral tolerance induction: in-hospital "rush" phase. Eur Ann Allergy Clin Immunol. 2012;44(1):18-25 
72. Martorell A, et al. Oral desensitization as a useful treatment in 2-year-old children with cow's milk allergy. Clin Exp Allergy. 2011;41(9):1297-1304.

73. de Boissieu D, Dupont C. Sublingual immunotherapy for cow's milk protein allergy: a preliminary report. Allergy. 2006;61(10):1238-1239.

74. Enrique E, et al. Sublingual immunotherapy for hazelnut food allergy: a follow-up study. Ann Allergy Asthma Immunol. 2008;100(3):283-284.

75. Yeung JP, Kloda LA, McDevitt J, Ben-Shoshan M, Alizadehfar R. Oral immunotherapy for milk allergy. Cochrane Database Syst Rev. 2012;11:CD009542.

76. Keet CA, et al. The safety and efficacy of sublingual and oral immunotherapy for milk allergy. J Allergy Clin Immunol. 2012;129(2):448-455

77. Allam JP, et al. Distribution of Langerhans cells and mast cells within the human oral mucosa: new application sites of allergens in sublingual immunotherapy? Allergy. 2008;63(6):720-727.

78. Wessel F, Chartier A, Meunier JP, Magnan A. Safety and tolerability of an SQ-standardized GRAss ALlergy immunotherapy tablet (GRAZAX(R)) in a real-life setting for three consecutive seasons - the GRAAL trial. Clin Drug Investig. 2012;32(7):451-463.

79. Keet CA, Seopaul S, Knorr S, Narisety S, Skripak J, Wood RA. Long-term follow-up of oral immunotherapy for cow's milk allergy. J Allergy Clin Immunol. 2013;132(3):737-739.

80. Fleischer DM. The natural history of peanut and tree nut allergy. Curr Allergy Asthma Rep. 2007;7(3):175-181.

81. Savage JH, Courneya JP, Sterba PM, Macglashan DW, Saini SS, Wood RA. Kinetics of mast cell, basophil, and oral food challenge responses in omalizumab-treated adults with peanut allergy. J Allergy Clin Immunol. 2012;130(5):1123-1129.

82. Leung DY, et al. Effect of anti-IgE therapy in patients with peanut allergy. $N$ Engl J Med. 2003;348(11):986-993.

83. Massanari M, et al. Effect of pretreatment with omalizumab on the tolerability of specific immunotherapy in allergic asthma.J Allergy Clin Immunol. 2010;125(2):383-389

84. Kopp MV, et al. Combination of omalizumab and specific immunotherapy is superior to immunotherapy in patients with seasonal allergic rhinoconjunctivitis and co-morbid seasonal allergic asthma. Clin Exp Allergy. 2009;39(2):271-279.

85. Casale TB, et al. Omalizumab pretreatment decreases acute reactions after rush immunotherapy for ragweed-induced seasonal allergic rhinitis. J Allergy Clin Immunol. 2006;117(1):134-140.

86. Kuehr J, et al. Efficacy of combination treatment with anti-IgE plus specific immunotherapy in polysensitized children and adolescents with seasonal allergic rhinitis. J Allergy Clin Immunol. 2002;109(2):274-280

87. Klunker $\mathrm{S}$, et al. Combination treatment with omalizumab and rush immunotherapy for ragweed-induced allergic rhinitis: Inhibition of IgEfacilitated allergen binding. J Allergy Clin Immunol. 2007;120(3):688-695

88. Schneider LC, Rachid R, LeBovidge J, Blood E, Mittal M, Umetsu DT. A pilot study of omalizumab to facilitate rapid oral desensitization in high-risk peanut-allergic patients. J Allergy Clin Immunol. 2013;132(6):1368-1374.

89. Nadeau KC, Schneider LC, Hoyte L, Borras I, Umetsu DT. Rapid oral desensitization in combination with omalizumab therapy in patients with cow's milk allergy. J Allergy Clin Immunol. 2011;127(6):1622-1624.

90 . Hemmi H, et al. Skin antigens in the steady state are trafficked to regional lymph nodes by transforming growth factor-beta1-dependent cells. Int Immunol. 2001;13(5):695-704

91. Akei HS, Mishra A, Blanchard C, Rothenberg ME. Epicutaneous antigen exposure primes for experi- mental eosinophilic esophagitis in mice. Gastroenterology. 2005;129(3):985-994.

92. Mondoulet $\mathrm{L}$, et al. Intact skin and not stripped skin is crucial for the safety and efficacy of peanut epicutaneous immunotherapy (EPIT) in mice. Clin Transl Allergy. 2012;2(1):22.

93. Mondoulet L, et al. Epicutaneous immunotherapy (EPIT) blocks the allergic esophagogastro-enteropathy induced by sustained oral exposure to peanuts in sensitized mice. PLoS One. 2012;7(2):e31967.

94. Mondoulet L, Dioszeghy V, Ligouis M, Dhelft V, Dupont C, Benhamou PH. Epicutaneous immunotherapy on intact skin using a new delivery system in a murine model of allergy. Clin Exp Allergy. 2010;40(4):659-667.

95. Senti G, et al. Epicutaneous allergen-specific immunotherapy ameliorates grass pollen-induced rhinoconjunctivitis: a double-blind, placebo-controlled dose escalation study. J Allergy Clin Immunol. 2012;129(1):128-135

96. Dioszeghy V, et al. Epicutaneous immunotherapy results in rapid allergen uptake by dendritic cells through intact skin and downregulates the allergen-specific response in sensitized mice. J Immunol. 2011;186(10):5629-5637.

97. Rotiroti G, Shamji M, Durham SR, Till SJ. Repeated low-dose intradermal allergen injection suppresses allergen-induced cutaneous late responses. J Allergy Clin Immunol. 2012;130(4):918-924.

98. Hylander T, Latif L, Petersson-Westin U, Cardell LO. Intralymphatic allergen-specific immunotherapy: an effective and safe alternative treatment route for pollen-induced allergic rhinitis. J Allergy Clin Immunol. 2013;131(2):412-420.

99. Senti G, et al. Intralymphatic immunotherapy for cat allergy induces tolerance after only 3 injections. J Allergy Clin Immunol. 2012;129(5):1290-1296.

100.Senti G, Johansen P, Kundig TM. Intralymphatic immunotherapy: from the rationale to human applications. Curr Top Microbiol Immunol. 2011:352:71-84.

101.von Moos S, Kundig TM, Senti G. Novel administration routes for allergen-specific immunotherapy: a review of intralymphatic and epicutaneous allergen-specific immunotherapy. Immunol Allergy Clin North Am. 2011;31(2):391-406.

102.López-Expósito I, Castillo A, Yang N, Liang B, Li XM. Chinese herbal extracts of Rubia cordifolia and Dianthus superbus suppress IgE production and prevent peanut-induced anaphylaxis. Chin Med. 2011;6:35.

103. Qu C, Srivastava K, Ko J, Zhang TF, Sampson HA, Li XM. Induction of tolerance after establishment of peanut allergy by the food allergy herbal formula-2 is associated with up-regulation of interferongamma. Clin Exp Allergy. 2007;37(6):846-855.

104. Wang J, et al. Safety, tolerability, and immunologic effects of a food allergy herbal formula in food allergic individuals: a randomized, double-blinded, placebo-controlled, dose escalation, phase 1 study. Ann Allergy Asthma Immunol. 2010;105(1):75-84.

105. Li XM, et al. Food Allergy Herbal Formula-1 (FAHF-1) blocks peanut-induced anaphylaxis in a murine model. J Allergy Clin Immunol. 2001;108(4):639-646.

106. Patil SP, et al. Clinical safety of Food Allergy Herbal Formula-2 (FAHF-2) and inhibitory effect on basophils from patients with food allergy: Extended phase I study. J Allergy Clin Immunol. 2011;128(6):1259-1265.

107. Patel D, et al. Fel d 1-derived peptide antigen desensitization shows a persistent treatment effect 1 year after the start of dosing: A randomized, placebo-controlled study. J Allergy Clin Immunol. 2013;131(1):103-109.

108. Worm M, et al. Development and preliminary clinical evaluation of a peptide immunotherapy vaccine for cat allergy. J Allergy Clin Immunol. 2011;127(1):89-97.
109.Yang M, Yang C, Mine Y. Multiple T cell epitope peptides suppress allergic responses in an egg allergy mouse model by the elicitation of forkhead box transcription factor 3- and transforming growth factor-beta-associated mechanisms. Clin Exp Allergy. 2010;40(4):668-678.

110.Swoboda I, et al. A general strategy for the generation of hypoallergenic molecules for the immunotherapy of fish allergy. J Allergy Clin Immunol. 2013;132(4):979-981.

111. Prickett SR, et al. Ara h 1 CD4+ T cell epitope-based peptides: candidates for a peanut allergy therapeutic. Clin Exp Allergy. 2013;43(6):684-697.

112.Li XM, Srivastava K, Huleatt JW, Bottomly K, Burks AW, Sampson HA. Engineered recombinant peanut protein and heat-killed Listeria monocytogenes coadministration protects against peanutinduced anaphylaxis in a murine model. J Immunol. 2003;170(6):3289-3295.

113. Wood RA, et al. A phase 1 study of heat/phenolkilled, E. coli-encapsulated, recombinant modified peanut proteins Ara h 1, Ara h 2, and Ara h 3 (EMP123) for the treatment of peanut allergy. Allergy. 2013;68(6):803-808

114.Xu W, Tamura T, Takatsu K. CpG ODN mediated prevention from ovalbumin-induced anaphylaxis in mouse through B cell pathway. Int Immunopharmacol. 2008;8(2):351-361.

115.San Roman B, Irache JM, Gomez S, Gamazo C, Espuelas S. Co-delivery of ovalbumin and $\mathrm{CPG}$ motifs into microparticles protected sensitized mice from anaphylaxis. Int Arch Allergy Immunol. 2009;149(2):111-118.

116.Adel-Patient K, Ah-Leung S, Bernard H, DurieuxAlexandrenne C, Creminon C, Wal JM. Oral sensitization to peanut is highly enhanced by application of peanut extracts to intact skin, but is prevented when $\mathrm{CPG}$ and cholera toxin are added. Int Arch Allergy Immunol. 2007;143(1):10-20.

117. Kulis M, Gorentla B, Burks AW, Zhong XP. Type B $\mathrm{CpG}$ oligodeoxynucleotides induce Th1 responses to peanut antigens: modulation of sensitization and utility in a truncated immunotherapy regimen in mice. Mol Nutr Food Res. 2013;57(5):906-915.

118.Zhu FG, Kandimalla ER, Yu D, Agrawal S. Oral administration of a synthetic agonist of Toll-like receptor 9 potently modulates peanut-induced allergy in mice. J Allergy Clin Immunol. 2007; 120(3):631-637

119. Creticos PS, et al. Immunotherapy with a ragweedtoll-like receptor 9 agonist vaccine for allergic rhinitis. N Engl J Med. 2006;355(14):1445-1455.

120.Shibata Y, Foster LA, Bradfield JF, Myrvik QN. Oral administration of chitin down-regulates serum IgE levels and lung eosinophilia in the allergic mouse. J Immunol. 2000;164(3):1314-1321.

121. Bae MJ, Shin HS, Kim EK, Kim J, Shon DH. Oral administration of chitin and chitosan prevents peanut-induced anaphylaxis in a murine food allergy model. Int J Biol Macromol. 2013;61:164-168.

122. Liu Y, et al. Blockade of peanut allergy with a novel Ara h 2-Fcgamma fusion protein in mice. J Allergy Clin Immunol. 2013;131(1):213-215.

123. Roy K, Mao HQ, Huang SK, Leong KW. Oral gene delivery with chitosan - DNA nanoparticles generates immunologic protection in a murine model of peanut allergy. Nat Med. 1999;5(4):387-391.

124.Liu MA. DNA vaccines: an historical perspective and view to the future. Immunol Rev. 2011; 239(1):62-84.

125. Jouvin $\mathrm{MH}$, Kinet JP. Trichuris suis ova: testing a helminth-based therapy as an extension of the hygiene hypothesis. J Allergy Clin Immunol. 2012;130(1):3-10.

126. Traister RS, Green TD, Mitchell L, Greenhawt M. Community opinions regarding oral immunotherapy for food allergies. Ann Allergy Asthma Immunol. 2012;109(5):319-323. 